\title{
Asia's Declining Death Penalty
}

\section{DAVID T. JOHNSON}

$\mathrm{F}$

OR MOST CULTURES AND most of human history, the death penalty was taken for granted and directed at a wide range of offenders. In ancient Israel, death was prescribed for everything from murder and magic to blasphemy, bestiality, and cursing one's parents. In eighteenth-century Britain, more than 200 crimes were punishable by death, including theft, cutting down a tree, and robbing a rabbit warren. China of the late Qing dynasty had some 850 capital crimes, many reflecting the privileged position of male over female and senior over junior.

In the past half century, there has been a remarkable decline of capital punishment in many parts of the world. As of 1970, only 21 nations had abolished capital punishment for all crimes or for "ordinary offenses" (all crimes except insurrection and offenses committed in wartime); today the total is 103, and 36 more nations retain it in law but have not executed anyone for at least 10 years. By comparison, 58 nations retain capital punishment and continue to conduct executions. At present, therefore, 70 percent of all countries have abolished capital punishment in law or practice.

Capital punishment is also an endangered species in several regions of the world, including Europe, which is a death penalty-free zone except for the dictatorship of Belarus, and Central and South America, where a tradition of abolition holds sway everywhere except Guatemala and Guyana. In Africa, only two to seven nations (out of 54) used execution in any one year between 2000 and 2006. ${ }^{1}$

But if the death penalty is declining, it has not disappeared. There remain four strongholds in the world today: the United States, where 35 states and the federal system retain capital punishment (and where the vast majority of executions are concentrated in a handful of Southern states); the Caribbean, where 11 of 13 countries (with a combined population of 5 million) retain the death penalty but rarely carry out executions; the Muslim-majority nations of the Middle East; and Asia, where 60 percent of the world's population live and more than 90 percent of the world's executions have taken place in recent years-the large majority in China. 


\section{Varieties of Policy}

There is great variation in death penalty policy within the Asia region. Figure 1 uses the categories employed by Amnesty International to depict some of the variety.

The 29 Asian jurisdictions divide into 13 with both legal retention and at least one execution in the previous 10 years, and 16 with either formal abolition or "de facto" abolition status (more than 10 years without execution). Clearly, there has been much abolitionist activity in the Asia region.

But the almost 50-50 split in figure 1 fails to reflect the real balance of death penalty policy in Asia because nearly all of the major population centers in the region remain retentionist. Indeed, about 95 percent of the residents of Asia live in jurisdictions that continue to use capital punishment. This patternmore populous states are more likely to retain the death penalty-prevails not only in Asia but also worldwide.

Yet of the 13 Asian nations in the retentionist category, only four use execution with any frequency - as a regular criminal sanction rather than a one-in-a-thousand penalty of chiefly symbolic importance. They are China, Vietnam, North Korea, and Singapore: three authoritarian states that are (or were) communist, and one on the right that has been called "a post-Maoist model of the Chinese future." ${ }^{2}$ None of these high-use states provides decent death penalty data (the number of persons executed in China is not only unavailable, it is a state secret, the disclosure of which triggers criminal liability). But reasonable estimates can be made. China probably executed an average of 15,000 persons per year from 1998 to 2001. ${ }^{3}$ That is as many persons kicked off the planet each year as were executed in America from 1640 to the present, but it is a small fraction of the volume of state killing that occurred while Mao ruled the country.

Singapore also administers an aggressive death penalty system-one in which judges must impose a sentence of death on every defendant convicted of murder or drug trafficking. It is instructive to compare the most business-friendly city in the world with the city of Houston-the most aggressive executing jurisdiction in the most aggressive executing state in the most aggressive executing democracy in the world. From 1976, when the U.S. Supreme Court reinstated capital punishment, until 2004, Harris County, Texas-the Houston metropolitan areaaccounted for 73 executions, seven more than the nation of Japan had over the

\footnotetext{
${ }^{2}$ Ian Buruma, Bad Elements: Chinese Rebels from Los Angeles to Beijing (New York: Random House, 2001), 125. Buruma and others have disparaged Singapore as "Disneyland with the death penalty."

${ }^{3}$ The source for the 15,000 figure is confidential files from the Chinese Communist Party that were leaked to a writer abroad; see Andrew J. Nathan and Bruce Gilley, China's New Rulers: The Secret Files (New York: New York Review Books, 2003), 218. Other execution estimates for China can be found in Johnson and Zimring, The Next Frontier, 231-43.
} 


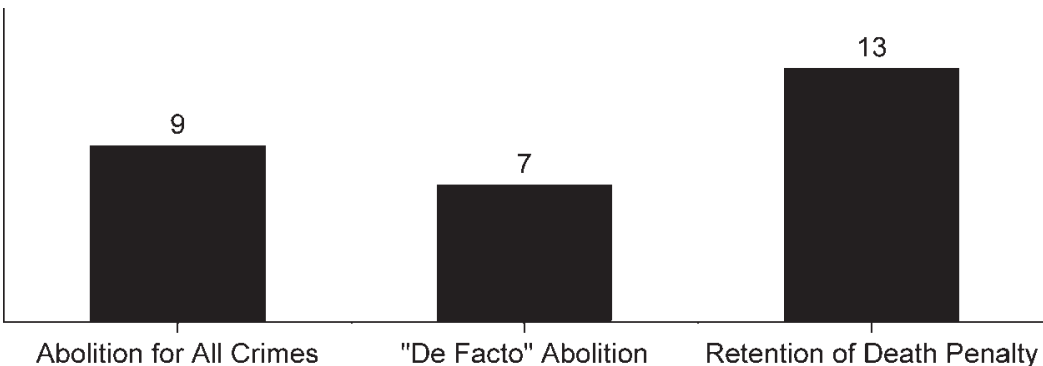

Figure 1. Status of the death penalty in 29 Asian Jurisdictions. As of November 2009, the jurisdictions are as follows. Abolition for all crimes: Australia (abolished in 1985), Bhutan (2004), Cambodia (1989), East Timor (1999), Hong Kong (1993), Macao (n.a.), Nepal (1997), New Zealand (1989), the Philippines (2006). "De facto" abolition: Brunei Darussalam (last execution in 1957), Laos (1989), Maldives (1952), Myanmar (1989), Papua New Guinea (1950), South Korea (1997), Sri Lanka (1976). Retention: Bangladesh, China, India, Indonesia, Japan, Malaysia, Mongolia, North Korea, Pakistan, Singapore, Taiwan, Thailand, Vietnam.

Note: (1) No jurisdiction in Asia has abolished capital punishment for "ordinary crimes only." (2) The "Special Administrative Regions" of Hong Kong and Macao do not have capital punishment, but offenders can be executed in China through the process of "rendition."

Source: Johnson and Zimring, p. 16.

same period. Singapore, by contrast, with a population only a little larger than Houston and a homicide rate one-tenth as high, had at least 76 executions in 1994, 73 in 1995, and 76 in 2000-2. Until Singapore's execution rate started to decline after 2002, the city-state was rightly considered the world execution capital.

But in recent years there have been significant execution declines in both Singapore and China. In Singapore, the 14 executions that occurred from 2005 to 2008 were less than one-tenth the total (166) for 1995 to 1998. And in China, the 15,000 executions per year in the late 1990s had fallen to 5,000 7,000 by 2008 - a decline of more than half in only one decade. ${ }^{4}$

Figure 1 does not reflect all of the variety in Asian death penalty policies. Compare China and India, the world's two most populous countries, both classified as "retentionist." India executed one person in the 10 years between 1998 and 2007, for an annual rate per million persons that is $1 / 3,000$ th that of the United States over the same period of time. If the rest of the world shared India's low rate, there would be, worldwide, less than one execution per year. China's execution rate, by contrast, is at least 50,000 times that of India. A difference of degree this vast is also a difference in kind that is not captured by the usual death penalty categories.

Figure 1 also does not display how common discretionary nonexecution interludes are in nations that retain capital punishment. Moratoria have occurred in India (1998-2003 and 2005-8), Japan (1989-92), Thailand (1988-95 and

\footnotetext{
${ }^{4}$ One source for the recent China estimate is John Kamm, director of the Dui Hua Foundation,
} quoted in Bill Schiller, "In China, a Quiet Push against Executions," Toronto Star, March 29, 2009. 
2004-8), Malaysia (1969-80, 1997-2000, and 2003-5), Bangladesh (1989-92 and 1998-2001), and Indonesia (1949-73 and 1996-2000). The last three countries are interesting because they are Muslim-majority nations that execute at very low rates. Nations with large Islamic populations retain capital punishment in Asia, as they do in North Africa and the Middle East, but in Asia, which is home to about two-thirds of the world's Muslims, those nations are concentrated at the low execution rate end of the retentionist category. If Islam is an obstacle to death penalty reform in countries with large Muslim populations-as some analysts argue ${ }^{5}$ it is not obviously so in the region of the world where Muslims are most numerous.

\section{Causes}

The decline of capital punishment in most parts of Asia is explained by many of the same causes that account for the decline of capital punishment in other parts of the world. One noncause is public opinion. As table 1 shows, there is strong support for capital punishment everywhere in Asia where the issue has been studied-whatever the execution rate. And in Asia as elsewhere, jurisdictions that have abolished the death penalty have done so despite the fact of strong majority support at the point of abolition. In Hong Kong, for example, about two-thirds of the public supported capital punishment at the time of abolition, a proportion close to the levels of support that currently exist in Japan, South Korea, and Taiwan. This pattern of abolition despite support is consistent with the experiences of Western nations such as Great Britain, Canada, and Germany. In these democratic settings, the political momentum for reform was achieved through "leadership from the front," and something similar helps explain the huge execution declines in South Korea and Taiwan. Not long ago, these two nations ranked among the most aggressive executing states in Asia, with Taiwan's execution rates not far below those of its huge sibling to the west. But as of 2010, South Korea has not executed anyone since 1997, and Taiwan has not executed since 2005. In both places, the critical leadership came from the very top of the power structure-Presidents Kim Dae Jung and Roh Moo Hyun in South Korea, and President Chen Shui-bian in Taiwan.

Leadership from the front on capital punishment is a two-way street in contemporary Asia because government elites also provide the major impetus for maintaining high rates of execution, or even increasing them. When China embarks on one of its "Strike Hard" campaigns, the prime mover is Beijing, not populist sentiment in the provinces. Similarly, the main difference that explains the large and long-standing gap in execution rates between Singapore

${ }^{5}$ Roger Hood, "Capital Punishment: A Global Perspective," Punishment \& Society 3, no. 3 (2001): 341. 
Table 1. The Death Penalty and Public Opinion in Asia.

\begin{tabular}{lccl}
\hline Nation & Survey Year & Percent Support & \multicolumn{1}{c}{ Execution Level } \\
\hline China & 2008 & $58 \% *$ & High \\
South Korea & 1999 & $66 \%$ & Low (none since 1997) \\
Hong Kong & 1986 & $68 \%$ *** & Low (none since 1966) \\
Philippines & 1999 & $80 \%$ & Low (none since 2000) \\
Taiwan & 2001 & $80 \%$ & Low (none since 2005) \\
Japan & 2005 & $81 \%$ & Medium \\
Thailand & 2005 & $84 \%$ & Medium \\
Singapore & 2006 & $96 \%$ & High
\end{tabular}

*The figure for China comes from a survey conducted in Beijing, Hubei, and Guangdong; see Dietrich Oberwittler and Shenghui Qi, "Public Opinion and the Death Penalty in China," Max Planck Institute for Foreign and International Criminal Law, 2009; http://www.mpicc.de/shared/data/pdf/ forschung_aktuell_41.pdf

${ }^{* *}$ Hong Kong is treated separately from China because its death penalty decisions are made independently.

Source: Johnson and Zimring, p.302.

and Malaysia is not between the average "person on the street" in these two nations - unless that person in Singapore happens to be Lee Kuan Yew. In Singapore and China, and in North Korea and Vietnam as well, the key determinant of high execution levels is the preference of strong governments with pervasive authority over executive and judicial actions. In these settings, leadership comes from the front on almost all matters, and it frequently contradicts public opinion. Whatever the governmental system, the key proximate cause of substantive change in death penalty policy is the leadership of political elites.

Asia shares with the rest of the world two other proximate causes of death penalty decline. The first is the fall of authoritarian regimes. In Germany, Italy, Portugal, and Spain, the death penalty disappeared after authoritarian governments did. Similar abolitions have occurred in Asia-in Cambodia (1989), East Timor (1999), and the Philippines (1987) — and major execution declines also followed the turns toward democracy in South Korea and Taiwan. When a repressive regime is replaced, one common way for the new government to distance itself from the old is to renounce this form of state killing.

A second common pattern is the decline of capital punishment after a left-liberal party takes control of government. This is what explains the cessation of executions in South Korea immediately after Kim Dae Jung became president in 1998, and it also helps explain the sustained drop in executions in Taiwan after Chen Shui-bian became president in 2000. The absence of these two causes may also account for the persistence of capital punishment in Japan-one of only two developed democracies in the world that retains the death penalty and continues to carry out executions on a regular basis (the other is the United States). After Japan's defeat in the Pacific War, occupation authorities decided to keep capital punishment despite imposing many major reforms on Japan's previously 
authoritarian polity. The long hegemony of the conservative Liberal Democratic Party from 1955 until 2009, when the Democratic Party of Japan won a upset national election, meant that Japan never had the kind of right-to-left political transition that precipitated major death penalty declines in South Korea and Taiwan and outright abolitions in England, Austria, and France.

Economic development also tends to stimulate death penalty decline, though this is by no means an iron law. In 2006, Asia’s least prosperous nations were twice as likely as its most prosperous ones to carry out executions, while nations with middling levels of per capita gross domestic product were in the middle position on execution prevalence. ${ }^{6}$ But of course, economic prosperity is neither a necessary nor a sufficient condition for abolition. Cambodia, Nepal, Bhutan, and East Timor are some of Asia's poorest states, and the Philippines lags well behind the monumental success stories of East Asian economic development, yet all of these nations have abolished capital punishment in recent years. ${ }^{7}$ Conversely, Japan and Singapore are two of Asia's most prosperous places, and both continue to conduct executions. On average, however, there are fewer executions in the more developed nations of Asia because economic development tends to foster technological, educational, and even moral improvements that ultimately produce pressure for political reform. ${ }^{8}$

The transnational human rights movement has also helped curb capital punishment. When death penalty policy is discussed in contemporary Asia, questions about human rights and the appropriate limits on government power are usually close to the center of debate. ${ }^{9}$ This distinguishes Asia from Europe, where neither friends nor foes of capital punishment made any serious effort to build a position on the death penalty into a larger framework of human rights in law or moral argument until after Western Europe had already become abolitionist. The framing of capital punishment as a human rights issue only gained traction in Europe in the 1980s. Since then, that frame has been exported to the rest of the world - including Asia-with missionary vigor.

In the states of Central Europe that had been under Soviet domination prior to 1989 , the human rights frame for capital punishment-and regional institutions and mechanisms for enforcing it (such as the requirement that no country be allowed to apply for membership in the European Union unless, as a precondition, it abandons capital punishment)-helped bring about the fastest and most complete regional abolition in history. In Asia as well, human

\footnotetext{
${ }^{6}$ Johnson and Zimring, The Next Frontier, 33, 293.

${ }^{7}$ These nations also show that extrajudicial executions do not necessarily end when judicial executions do. On the relationship between different kinds of state killing in Asia, see Johnson and Zimring, The Next Frontier, 443-51.

${ }^{8}$ Benjamin M. Friedman, The Moral Consequences of Economic Growth (New York: Alfred A. Knopf, 2005).

${ }^{9}$ Sangmin Bae, When the State No Longer Kills: International Human Rights Norms and Abolition of Capital Punishment (Albany: State University of New York Press, 2007).
} 
rights norms have mattered, albeit less than in Central Europe because Asia has few regional organizations to parallel those that have existed in Europe for decades. More generally, Asia now differs from Europe and Africa in that the most important sphere of influence on death penalty policy is still national, not international or regional. The power to determine death penalty policy seems likely to remain a domestic prerogative for some time to come.

\section{Consequences}

Many Asian governments that retain capital punishment argue that it is needed in order to control crime. In China, for example, the Chinese Communist Party says that in the long run the country should and will abolish the death penalty - thereby conceding on the question of principle—but it claims capital punishment is needed at present in order to control a serious and growing crime problem. Similar assertions are made by the high-execution-rate states of Vietnam and Singapore, by low-rate states such as Indonesia and India, by states where executions have increased in recent years (Japan and Pakistan), and by states where executions have ceased (South Korea and Taiwan). If there is one thing that unites nations in the retentionist category, it is faith in the capacity of capital punishment to control crime.

That faith is probably misplaced. In Japan, executions fell from an average of 25 per year in the 1950s to an average of 1.5 per year in the 1980s - a decline of more than 90 percent during a period in which the population increased by more than a third—and yet Japan's homicide rate dropped 80 percent over the same period. In the last year that South Korea executed (1997), 23 persons were hanged-19 men and 4 women-all on the same day (December 30). Korea's execution record is similarly "lumpy" for the previous 35 years, with mass executions on a single day interrupting long periods-including nine calendar years-without any executions at all, yet there is no discernable difference in homicide between the months or years following mass execution and the months or years preceding it.

The most telling test of the capacity of capital punishment to deter homicide comes from Hong Kong and Singapore. These two jurisdictions are not twinsHong Kong is one-third more populous and 20 percent more ethnically Chinese - but they do resemble each other in many respects, with similar experiences of British colonialism, population densities, age distributions, per capita gross domestic products, economic growth rates, birth and migration rates, infant mortality rates, literacy rates, life expectancies, and gender-related development scores. The two cities also have death penalty policies that are as divergent as any can be: Hong Kong has had no executions since 1966 and formally abolished the death penalty in 1993, while Singapore went from no more than four or five executions a year in the late 1980s to the world's highest execution 
rates in the mid-1990s before reducing executions by more than 90 percent in the subsequent decade. Singapore thus conducted two of the most dramatic death penalty "experiments" on record - a huge increase followed by an extraordinary decline. As Hong Kong was execution free throughout the same period, if the death penalty deters homicide, then we would expect to see major differences in these two cities' homicide trends. But we do not.

As figure 2 shows, the homicide rates in Hong Kong and Singapore have tracked each other closely for 35 years. Singapore's homicide decline starts well before the execution surge of the mid-1990s and continues thereafter, leaving the city slightly safer in an era of 5 executions per year (2005-7) than it was with 50 or more (1994-96). And Hong Kong's homicide experience is so similar that the two lines appear to be holding hands since the early 1970s. By the end of the time series depicted in figure 2, Hong Kong, with no executions for 41 years, is every bit as safe a city as Singapore.

This tale of two cities is notable not only for what it suggests about the death penalty's limited capacity to deter homicide but also because Singapore's "overwhelming commitment to pragmatism" has been called "as pure a utilitarianism as is humanly possible." ${ }^{\prime \prime}$ If Singapore gets any marginal deterrence from the death penalty, it must be for drug crimes, not homicide. Yet despite the importance of this policy question and frequent claims by Singapore's government that the death penalty deters drug offending, it refuses to release the data that would enable its utilitarian assertions to be tested. One can only wonder why. ${ }^{11}$

One may also wonder whether Asian nations that abolish capital punishment miss it when it is gone. The Philippines did—and then it realized it should be careful what it wishes for. The Philippines first abolished the death penalty in 1987, after Ferdinand Marcos was driven from power, and then reinstated it in 1993 by passing one of the most expansive capital statutes in Asia. After executing six men by lethal injection in 1999 and one more in 2000, a moratorium on executions was imposed that lasted until a second abolition occurred, in the summer of 2006. The new death penalty reflected popular and political desire for a sanction that would deter crime and achieve retribution while being administered fairly and reliably. But in practice, the death penalty delivered none of those benefits while posing many serious problems, including bias against the poor, frequent mistakes of law and fact, and a failure to satisfy the burden of precision that is a necessary condition for principled retribution. In one case, President Joseph Estrada assented to a last-minute appeal for clemency from a Catholic bishop

\footnotetext{
${ }^{10}$ Michael Hor, "The Independence of the Criminal Justice System in Singapore," Singapore Journal of Legal Studies 2 (2002): 512.

${ }^{11}$ Singapore and fifteen other Asian nations retain death penalty laws on the books for drug offenders, but "no evidence of a statistical kind has been forthcoming to support [the] contention" that capital punishment deters drug crime in any of those jurisdictions. See Roger Hood and Carolyn Hoyle, The Death Penalty: A Worldwide Perspective (New York: Oxford University Press, 2008), 139.
} 


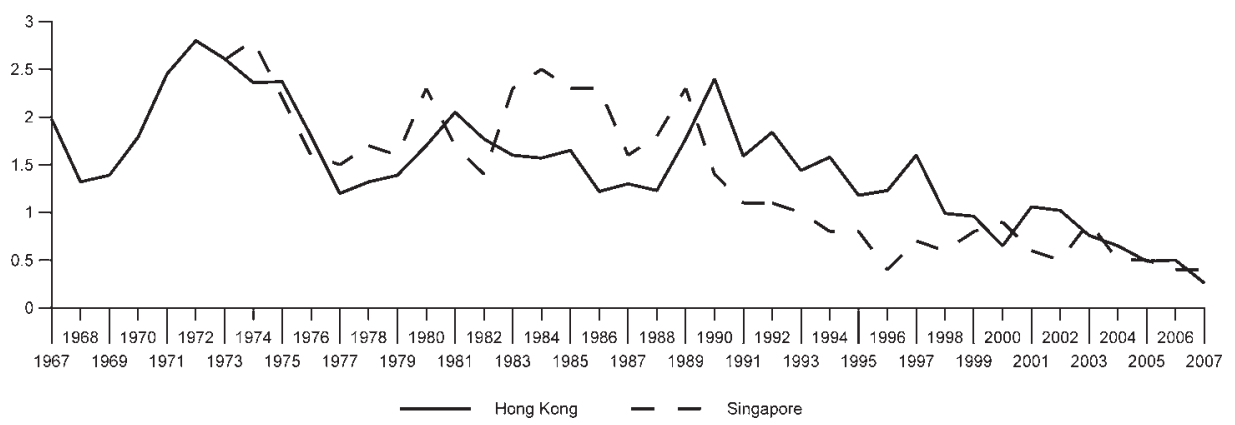

Figure 2. Homicide rates in Hong Kong and Singapore, 1967-2007.

Source: Franklin E. Zimring, Jeffrey Fagan, and David T. Johnson, "Executions, Deterrence, and Homicide: A Tale of Two Cities," Journal of Empirical Legal Studies (forthcoming, 2010); http://papers.ssm.com/sol3/ papers.cfnr/abstract_id=1436993.

and called the execution chamber from his home phone in order to stop the execution of convicted rapist Eduardo Agbayani, only to get a busy signal. By the time Estrada's aide reached the hotline in the presidential office, Agbayani had already been injected; he died two minutes after the mercy call arrived.

The ambivalence about abolition reflected in the Philippines is less pronounced in most other Asian jurisdictions that have rejected capital punishment. Even in the deeply Chinese society of Hong Kong, an analysis of the coverage of capital punishment by two large newspapers (the English-language South China Morning Post and the Chinese-language Singtao Daily) over a 12-year period following its 1993 abolition revealed barely a blip of interest in the subject, and pro-death penalty nostalgia was strikingly sparse. ${ }^{12}$ Capital punishment has apparently disappeared as a political question in Hong Kong, a vanishing act that may have implications for other Chinese societies-and other societies in Asia-in which leaders claim that local and "Asian" values cannot tolerate parting with a penalty that has deep cultural roots. In Hong Kong, if the death penalty ever had roots, they were shallow.

\section{Conclusion}

A leading proponent of seeing the world through Asian eyes argues that societies in Asia are succeeding again because they are implementing "Western best practices," from free market economics to science, meritocracy, and the rule of law. In his view, the continued rise of Asia is "irresistible."13

The continued fall of capital punishment in Asia is probably irresistible too, especially if one posits a future that brings more economic development and

\footnotetext{
${ }^{12}$ Johnson and Zimring, The Next Frontier, 373.

${ }^{13}$ Kishore Mahbubani, The New Asian Hemisphere: The Irresistible Shift of Global Power to the East (New York: Public Affairs, 2008).
} 
political change to the world's most dynamic region. But in formulating their death penalty policies, most Asian nations are not consciously emulating the abolitionist nations of Europe. If anything, the leading Western precedent for Asian death penalty policy is the United States, which defines itself as the archetypal liberal democracy and guardian of human rights (whatever the reality may be), while rejecting claims that capital punishment is a human rights issue. ${ }^{14}$ Because America's commitment to capital punishment may well be an obstacle to abolition in other parts of the world (would Japan keep capital punishment if the United States abolished?), it is not imitation of "Western best practices" that drives Asia toward abolition; it is economic, social, and political change of a broad and powerful kind.

The decline of the death penalty in Asia also seems to reflect a growing recognition that there are two ways to pose a question about the propriety of capital punishment. If one asks whether death is deserved for individual offenders such as Asahara Shoko, the guru who masterminded the sarin gas attacks in Tokyo, or Yoo Young-chul, the South Korean serial killer who confessed to killing 21 people (and to dining on some of them), then many Asians readily lean toward yes. The crimes are unspeakable, and the culpability great. But if one asks instead what ought to be the pivotal policy question-can a system of capital justice be constructed that reaches only the rare, right cases without also condemning the innocent or the undeserving? - then a decent regard for evidence requires rejection of an institution of punishment that is as unnecessary for crime control as it is impossible to administer in a manner that is fair, just, and accurate.

\footnotetext{
${ }^{14}$ For an explanation of America's commitment to capital punishment that is based on the history of race relations in that country, see Franklin E. Zimring, The Contradictions of American Capital Punishment (New York: Oxford University Press, 2003).
} 